\title{
MiR-221 Promotes Capan-2 Pancreatic Ductal Adenocarcinoma Cells Proliferation by Targeting PTEN-Akt
}

\author{
Wenzhuo Yang ${ }^{a}$ Yanning Yang ${ }^{a}$ Lu Xia $^{a}$ Yuefeng Yang ${ }^{a, b}$ Fei Wang ${ }^{a}$ Meiyi Song ${ }^{a}$ \\ Xiaoyu Chen ${ }^{\mathrm{a}}$ Jingqi Liu ${ }^{\mathrm{a}}$ Yang Song ${ }^{\mathrm{a}}$ Yingying Zhao Changqing Yanga
}

aDivision of Gastroenterology and Hepatology, Digestive Disease Institute, Shanghai Tongji Hospital, Tongji University School of Medicine, Shanghai, 'Division of Gastroenterology, Zhejiang Hospital, Hangzhou, China

\section{Key Words}

MiR-221 • Pancreatic ductal adenocarcinoma • Capan-2 • PTEN • Akt

\begin{abstract}
Background/Aims: MicroRNAs (miRNAs, miRs) have emerged as critical regulators of cancer cell proliferation. The effect of miR-221 on cancer cell growth could be significantly changeable in different cell lines. Although miR-221 was reported to promote the cell growth of pancreatic ductal adenocarcinoma (PDAC) cells, its role in Capan-2 cell line is largely unknown. Methods: Capan-2 cells were transfected with miR-221 mimics, inhibitors, or negative controls. Cell Counting Kit- 8 was used to determine cell viability. EdU staining and cell cycle analysis were used to measure cell proliferation. Western blotting was used to detect the expression levels of PTEN and phospho-Akt. The PI3K-Akt pathway activator SC-79 and inhibitor LY294002 were used to perform the rescue experiment in determining cell proliferation. Results: Overexpressing miR-221 significantly increased cell vitality and promoted cell proliferation and G1-to-S phase transition of the cell cycle in Capan-2 cells, while inhibition of miR-221 decreased that. The protein level of PTEN in Capan-2 cells was downregulated by overexpressing miR-221, while upregulated by inhibiting miR-221. Consistently, enhanced phosphorylation of $\mathrm{Akt}^{\mathrm{Ser} 473}$ was observed in miR-221 overexpressed Capan-2 cells, and the opposite result was found in miR221 inhibited cells. LY294002 restored the pro-proliferation effect of miR-221 on Capan-2 cells, while SC-79 had no additional effect on cell proliferation in Capan-2 cells transfected with miR-221 mimics. Conclusion: Our study indicates that miR-221 is an oncogenic miRNA which promotes Capan-2 cells proliferation by targeting PTEN-Akt pathway.
\end{abstract}

W. Yang, Y. Yang, L. Xia and Y. Yang contributed equally to this work.

Prof. Changqing Yang

and Dr. Yingying Zhao
Division of Gastroenterology and Hepatology, Digestive Disease Institute, Shanghai Tongji Hospital, Tongji University School of Medicine, 389 Xin Cun Road, Shanghai 200065, (China); E-Mail changqingyang_tj@hotmail.com / yingyingzhao_tj@163.com

\section{KARGER}




\section{Introduction}

Pancreatic ductal adenocarcinoma (PDAC) is the $13^{\text {th }}$ most commonly diagnosed cancer worldwide and the fifth cause of cancer death in the developed countries [1, 2]. Despite the improvement gained from medical advance, PDAC remains one of the highest mortality rates, and very low survival improvements have been made, a rate essentially unchanged over the course of the years [3,4]. Additionally, nearly $80 \%$ of patients who present with locally advanced or metastatic diseases have an extremely poor prognosis. The treatment of PDAC is primarily a combination of surgery and adjuvant chemotherapy, which is not satisfactory due to its limited efficacy [5]. Consequently, a much deeper understanding of the pathobiology and molecular mechanism of PDAC is essential to develop novel therapeutic strategies.

MicroRNAs (miRNAs, miRs) are a group of small noncoding RNAs with about 20 nucleotides in length [6,7], which post-transcriptionally regulate message RNA (mRNA), leading to the suppression of target gene expressions [8-10]. To date, microarray technology has revealed that differential miRNA expression patterns were tissue/cell type-specific, and even depended on the developmental stage of tumors. For that reason, studies have highlighted their importance in pathological activity, including tumor development [11-13]. miR-221 belongs to the miR-221/222 family, which locates on the X chromosome and shares some identical seed sequences with its homologous miRNA, miR-222 [14]. Accumulating evidence has indicated that miR-221 was an oncogene, which was up-regulated in a variety of cancers, including hepatocellular carcinoma, prostate adenocarcinoma, and colorectal carcinoma [15-18]. These results indicate that miR-221 may play significant roles in cancer development. Circulating miR-221 level has been detected to be markedly higher in PDAC patients compared to that in patients with benign pancreatic tumors or healthy controls [19]. However, the effect of miR-221 on cancer cell growth could be significantly changeable among cell lines, demonstrating that miR-221 might exhibit either pro- or anti-oncogenic roles in different cancer cell lines [20]. In a previous study on non-small cell lung cancer (NSCLC), miR-221 could promote cell growth in H460, while suppresses cell growth in four other NSCLC cell lines [20]. These data highlight the importance that the effect of miR-221 on cancer cell growth is highly needed to be tested in different cell lines.

In fact, different pancreatic adenocarcinoma cell lines have relative phenotypic differences in adhesion, migration, invasion, angiogenic potential, and tumorigenicity [21]. Recent studies have reported that miR-221 inhibition could attenuate cell proliferation in several human pancreatic adenocarcinoma cell lines, including BxPC-3, CFPAC-1 [22], MIA PaCa-2, PANC-1 [23], and AsPC-1 [24]. However, the effect of miR-221 on the proliferation of Capan-2 PDAC cell line is largely unknown. Indeed, here we aimed to clarify the functional role and the underlying molecular mechanism of miR-221 on the proliferation of Capan-2 cell line in vitro.

\section{Material and Methods}

\section{Materials and agents}

The PI3K-Akt pathway activator SC-79 [25] and inhibitor LY294002 [26] were purchased from Tocris Bioscience, UK. The Capan-2 cells were incubated with either SC-79 (4 $\mu \mathrm{g} / \mathrm{ml})$ or LY294002 (10 $\mu \mathrm{M})$ in the indicated experiments for $24 \mathrm{~h}$. RPMI-1640 medium and fetal bovine serum (FBS) was from Hyclone, USA. 100X penicillin-streptomycin was purchased from KeyGEN, China. 5-ethynyl-2'-deoxyuridine detection assay (Cell-Light ${ }^{\mathrm{TM}}$ EdU Apollo ${ }^{\circledR} 567$ In Vitro Imaging Kit) and miR-221 mimics/inhibitors were purchased from Ribobio, China. The sequences were designed as follows: miR-221 mimics, AGC UAC AUU GUC UGC UGG GUUUC; miR-221 inhibitor, GAA ACC CAG TCT CAA TGT AGC TCC GGA AAC CCA GTC TCA ATG TAGCT. CCK-8 assay was purchased from Dojindo, Japan. 


\section{Cellular Physiology Cell Physiol Biochem 2016;38:2366-2374 \begin{tabular}{ll|l} 
DOI: 10.1159/000445589 & $\begin{array}{l}\text { O 2016 The Author(s). Published by S. Karger AG, Basel } \\
\text { www.karger.com/cpb }\end{array}$
\end{tabular} \\ Yang et al.: MiR-221 Promotes Capan-2 Cells Proliferation}

Cell culture

Human PDAC cell line Capan-2 cell was purchased from Cell Bank of Type Culture Collection of Chinese Academy of Sciences (Shanghai, China). Capan-2 cells were maintained in RPMI-1640 medium supplemented with $10 \% \mathrm{FBS}, 100 \mathrm{U} / \mathrm{ml}$ penicillin and $100 \mu \mathrm{g} / \mathrm{ml}$ streptomycin. Cells were incubated at $37^{\circ} \mathrm{C}$ in a humidified atmosphere of $5 \% \mathrm{CO}_{2}$. The study was approved by the Ethics Committee of Tongji hospital, Tongji University, Shanghai, China.

\section{Cell transient transfection}

Capan-2 cells were seeded at density of $2 \times 10^{5} / \mathrm{ml}$ and allowed to adhere overnight. After that, Capan-2 cells were incubated with serum free medium for $6 \mathrm{~h}$, and were then transfected with miR-221 mimics (50 $\mathrm{nM}$ ), inhibitors (100 $\mathrm{nM}$ ) or their negative controls (NC) for $48 \mathrm{~h}$ using Lipofectamine 2000 (Invitrogen, USA) according to the manufacturer's instructions.

Real time quantitative PCR assay

Total RNA was isolated from Capan-2 cells using TRIZOL reagent (Invitrogen, USA). miR-221 real time PCR assays and reverse transcription reactions were performed using Bulge-Loop ${ }^{\text {TM }}$ miRNA qRT-PCR Primer Set (RiboBio, China) according to instructions.

\section{Cell vitality assay}

The effect of miR-221 on cell viability was determined using a Cell Counting Kit-8 (CCK-8) assay, which is based upon WST-8 [2-(2-methoxy-4- nitrophenyl)-3-(4-nitrophenyl)-5-(2, 4-disulfphenyl)-2Htetrazolium)] uptake. Cells (5 $\times 10^{3} /$ well) were seeded in 96-well plates and allowed to adhere overnight. After $48 \mathrm{~h}$ of miR-221 mimics/inhibitors and their NC transfection, 10ul CCK-8 solution was added to each well and incubated for $1 \mathrm{~h}$ at $37^{\circ} \mathrm{C}$, then the absorbance was measured at $450 \mathrm{~nm}$ using a spectrophotometer.

\section{EdU Proliferation Assay}

To access the effects of miR-221 in proliferative on Capan-2 cells, cells were pre-treated with $50 \mu \mathrm{M}$ 5-ethynyl-2'-deoxyuridine (EdU) before harvest. Then an Apollo staining was performed according to the instructions to detect the EdU positive cells using a fluorescence microscope [27].

Analysis of cell cycle distribution by flow cytometry

Capan-2 cells were transfected with miR-221 mimics or inhibitors and then incubated for $48 \mathrm{~h}$. After that, cells were collected and washed twice with PBS. Subsequently, cells were fixed in $70 \%$ ethanol (pre-cold at $-20^{\circ} \mathrm{C}$ temperature) overnight at $-20^{\circ} \mathrm{C}$. The fixed cells were then washed twice in ice-cold PBS and then incubated with RNase $(50 \mu \mathrm{g} / \mathrm{ml})$ for $15 \mathrm{~min}$. Subsequently, cells were stained with $50 \mu \mathrm{g} / \mathrm{mL}$ propidium iodide (PI) for $30 \mathrm{~min}$. The stained cells were then analyzed for their DNA content by using a Beckman flow cytometry. The results were analyzed by FlowJo software.

\section{Western blotting}

Capan-2 cells were collected and lysed in ice-cold RIPA buffer (Beyondtime, China) with 10nM PMSF. An analytical 10\% SDS-PAGE was performed, and $50 \mu \mathrm{g}$ of protein of each was added into each lane. For immunoblotting, proteins in the SDS gels were transferred to a polyvinylidene difluoride (PVDF) membrane by an electroblot apparatus. Antibodies against Akt (1:1000, Bioworld, USA), phospho-Akt ${ }^{\text {Ser473 }}$ (1:1000, Bioworld, USA) and PTEN (1:1000, Abcam, USA) were used to detect the protein level. $\beta$-actin was used as loading control to equal protein loading. The membrane was developed using enhanced chemiluminescence system (ECL, BioRad, USA).

\section{Statistical analysis}

Data were expressed as mean \pm SEM. The independent-samples T-test was used for comparisons between two groups. The one-way ANOVA test, followed by Bonferroni's post-hoc test, was performed to analyze difference among more than two groups. All analysis was performed using SPSS 19.0 software. P-value less than 0.05 was considered significant.

\section{KARGER}




\section{Results}

miR-221 promotes Capan-2 cells proliferation

miR-221 has been proved to be an oncogenesis miRNA in multiple cancers [28-31], and may as well be an anti-oncogenesis miRNA depending on different cancer cell lines [20]. Still, the role of miR-221 in human PDAC cell line Capan-2 cells remains unknown. To investigate the role of miR-221 in Capan-2 cell growth, we performed miR-221 gain-of-function and loss-of-function experiments.

Effects of miR-221 mimics and inhibitors were confirmed by quantitative real-time PCRs. As shown in Fig. 1, transfection of miR-221 mimic ( $50 \mathrm{nM}$ ) could significantly increase the miR-221 level in Capan-2 cells ( $p<0.01)$, while transfection of miR-221 inhibitor (100 $\mathrm{nM})$ could decrease that $(\mathrm{p}<0.01)$. We then detected the cell vitality with a CCK-8 assay. As shown in Fig. 2A, overexpressing miR-221 significantly increased cell vitality $(\mathrm{p}<0.01)$ and reduction of miR-221 deceased that in Capan-2 cells $(\mathrm{p}<0.01)$.

DNA synthesis is another important factor of cancer cell growth. For that reason, we used an EdU assay to assess the effect of miR-221 on Capan-2 cell DNA synthesis. As shown in Fig. 2B, overexpressing miR-221 led to increased EdU-positive cell population compared with NC-mimics treated cells $(\mathrm{p}<0.01)$, while inhibiting miR-221 significantly reduced EdU positive-cell population compared with $\mathrm{NC}$-inhibitor group $(\mathrm{p}<0.01)$, indicating miR-221 could induce the DNA synthesis of Capan-2 cells.

Malignant cells often show a dysregulated cell cycle, which is a crucial tumorous property that promotes tumor growth and invasion. Here, we used flow cytometry to detect the cell cycle distribution of Capan-2 cells transfected with miR-221 mimics. As shown in Fig. 2C, up-regulation of miR-221 led to an increased S phase cell population $(p<0.01)$ and decreased G1 phase cell population $(p<0.01)$ than that of NC-mimics transfected cells.

miR-221 targets PTEN-Akt pathway in Capan-2 cells

PTEN, p27 and p57, a type of well-established tumor suppressors, as well as PUMA, a pro-apoptosis factor, have been reported as direct target genes of miR-221 [23, 32]. However, whether they could be endogenously regulated by miR-221 in Capan-2 cells remains unclear. Using Western blotting, we found that the protein level of PTEN in Capan-2 cells was downregulated by overexpressing miR-221, while up-regulated by inhibiting miR-221 (Fig. 3A). Meanwhile, the protein levels of p27, p57, and PUMA remained unchanged (Fig. 3A). These data indicate that PTEN might be a target gene of miR-221 in Capan-2 cells.

A

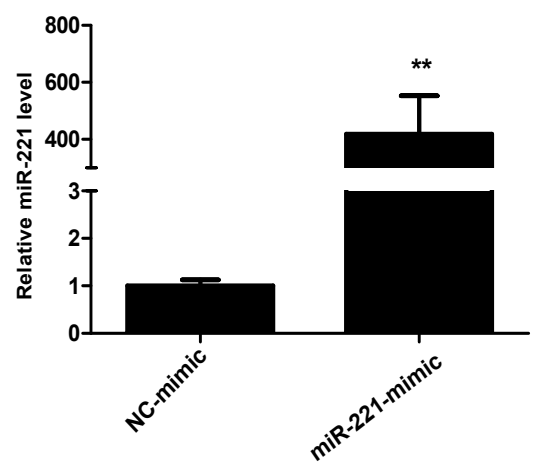

B

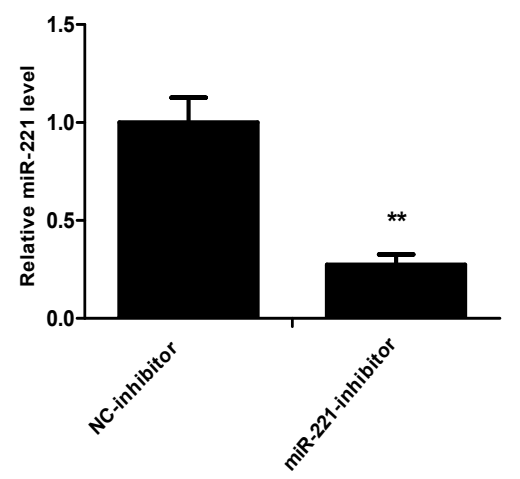

Fig. 1. Real time quantitative PCR results of miR-221. (A) The miR-221 level significantly increases in Capan-2 cells transfected with miR-221 mimics than transfected with negative control sequence (NC-mimics). (B) The miR-221 level significantly decreases in Capan-2 cells transfected with miR-221 inhibitors than transfected with negative control sequence (NC-inhibitors). ${ }^{* *}, p<0.01, \mathrm{n}=6$. 


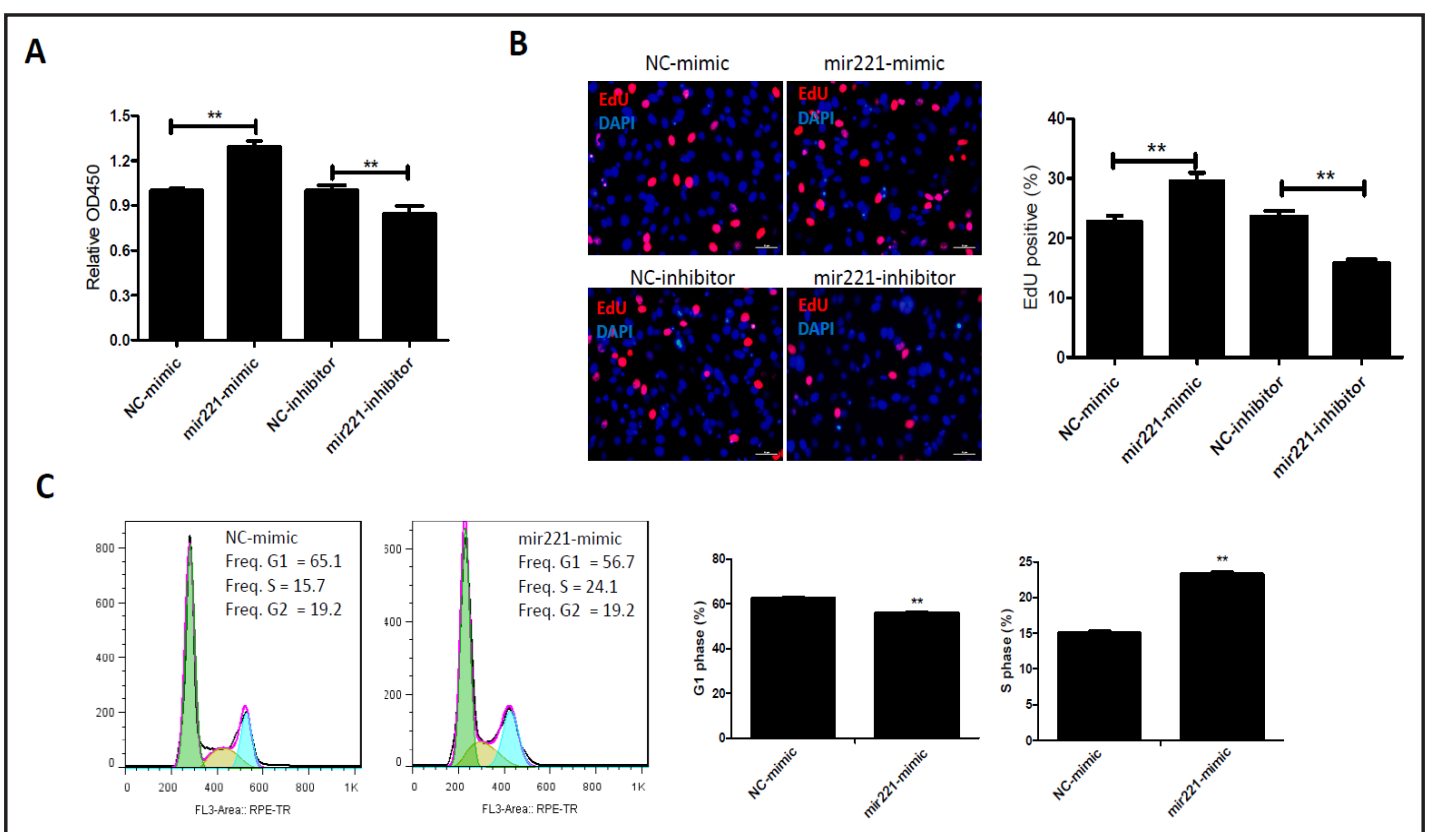

Fig. 2. miR-221 promotes Capan-2 cells proliferation. (A) CCK-8 assay shows miR-221 mimics enhances cell vitality, and inhibition of miR-221 leads to reduced cell vitality. ${ }^{* *}, p<0.01, \mathrm{n}=10$. (B) EdU assay shows overexpression of miR-221 increases cell proliferative rate, and inhibition of miR-221 leads to reduced cell proliferative rate. Red $=$ EdU positive cell, Blue $=$ DAPI. ${ }^{*}, p<0.01, \mathrm{n}=6$. (C) Overexpressing miR-221 increases $\mathrm{S}$ phase cell rate and reduces G1 phase cell rate, as demonstrated by flow cytometry. $* *, p<0.01, \mathrm{n}=4$.

PTEN is a crucial inhibitor for PI3k-Akt pathway, which dephosphorylates PIP3 to make PIP2 and inactivates Akt [33]. Akt activation is an important contributor to cancer genesis and development, by promoting cell proliferation, reducing cell apoptosis, and enhancing drug-resistance.[34-38]. To investigate the potential link between miR-221 and Akt activation, we detected the phosphorylation level of Akt in Capan-2 cells. As shown in Fig. 3A, we found enhanced phosphorylation of Akt $\mathrm{t}^{\mathrm{Ser} 473}$ in miR-221-overexpressed Capan-2 cells, and decreased phosphorylation of Akt ${ }^{\mathrm{Ser} 473}$ in miR-221-inhibited Capan-2 cells, while total Akt level remained unchanged. These results indicate that miR-221 targets PTEN-Akt pathway in Capan-2 cells.

\section{Akt mediates the proliferative effect of miR-221 on Capan-2 cells}

To confirm if Akt mediates the proliferative effect of miR-221 on Capan-2 cells, we firstly upregulated the miR-221 level by transfecting miR-221 mimics in Capan- 2 cells, and then we respectively treated the cells with PI3K-Akt activator SC-79 [39] or inhibitor LY294002 [40]. As shown in Fig. 3B, we found that treatment with LY294002 could abolish the proliferative effect of miR-221 on Capan- 2 cells. In addition, co-treatment with Akt activator SC-79 and miR-221 mimics had no additional effect on cell proliferation compared with cells transfected with miR-221 mimics alone. These results indicate that the effect of miR-221 on the proliferation of Capan-2 cells is mediated by Akt activation.

\section{Discussion}

PDAC is a major cause of cancer deaths all over the world [41, 42]. The prognosis of patients with PDAC is one of the worst in all cancer forms, despite that medical advances have been made in tumor diagnosis and treatment strategies during the past decades [43]. Consequently, it is of great importance to develop novel therapeutic methods to treat patients suffered from PDAC. 


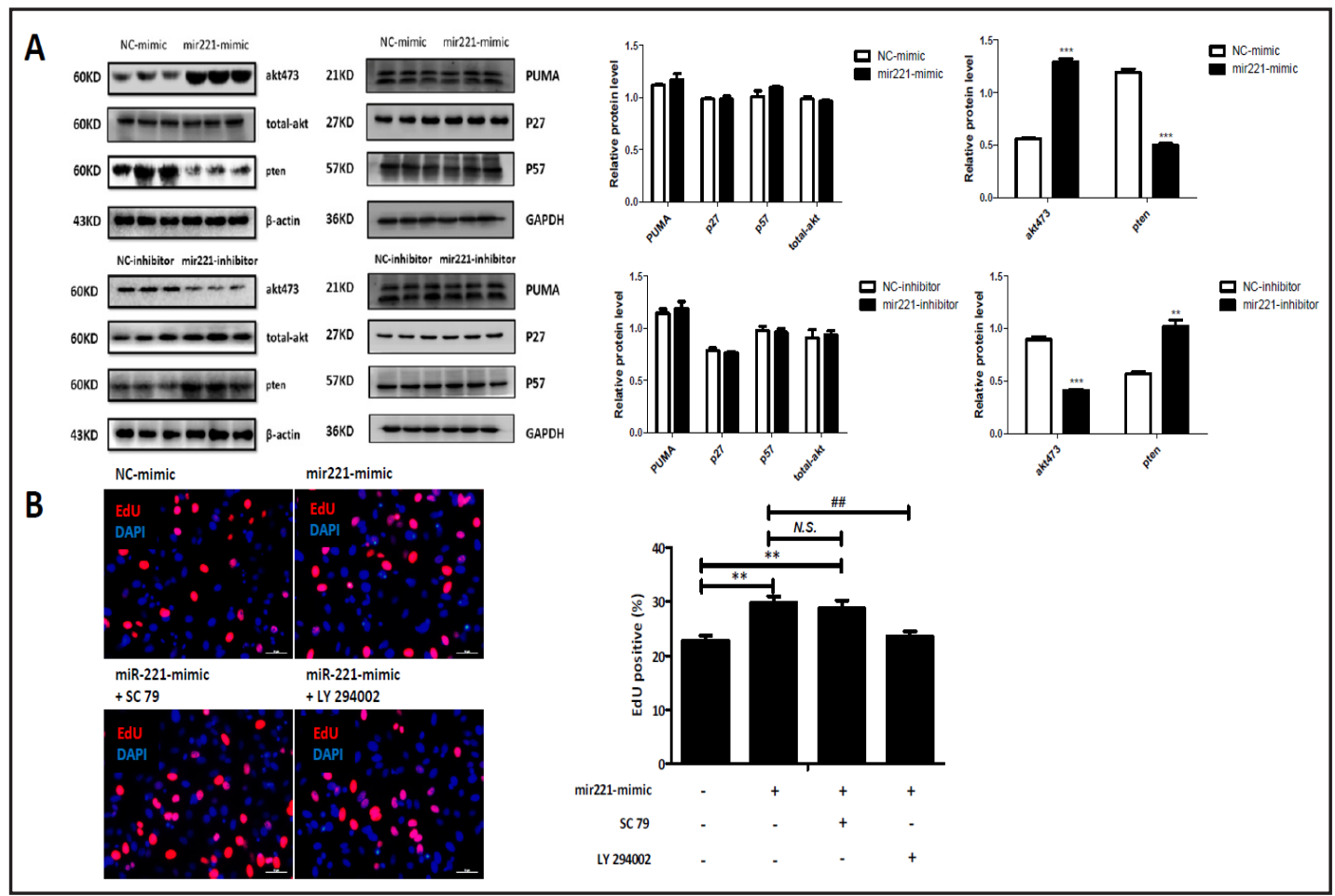

Fig. 3. PTEN-Akt pathway mediates the proliferative effect of miR-221 on Capan-2 cells. (A) Western blot assay shows that overexpressing miR-221 can reduce PTEN protein level and increase phospho-Akt ${ }^{\text {Ser473 }}$ level, while total Akt, PUMA, p27, and p57 levels do not change. Inhibition of miR-221 increases PTEN level and reduces phospho-Akt ${ }^{\mathrm{Ser} 43}$ level, while total Akt, PUMA, p27, and p57 levels do not change. (B) EdU assay shows both miR-221 mimics (+) group and miR-221 mimics (+) SC-79 (+) group has higher cell proliferative rate than miR-221(-) group. No significant difference is observed between miR-221 mimics (+) group and miR-221 mimics (+) SC-79 (+) group. No significant difference is observed between miR-221 (-) group and miR-221 (+) LY294002 (+) group. MiR-221 (+) LY294002 (+) group has lower cell proliferative rate than miR-221 mimics (+) group. Red $=$ EdU positive cell, Blue $=$ DAPI. ${ }^{* *}, p<0.01, \# \#, p<0.01$, N.S., No significance, $n=6$.

Overexpression of miR-221 accompanied by the inhibition of its target gene, PTEN, could significantly suppress tumor cell growth and proliferation in various cancers [44-47]. Our results are consistent with previous studies, implying the proliferative effect of miR-221 on PDAC Capan-2 cells. In the present study, we demonstrated that the elevated expression level of miR-221 could enhance cell vitality, induce proliferation, and promote cell cycle progression from G1 to $S$ phase in human pancreatic cancer cell line Capan-2 cells, whereas suppression of miR-221 had inverse effects in vitro. Therefore, it is very likely that inhibtion of miR-221 could be a therapeutic way for PDAC.

PTEN is proved as a direct target gene of miR-221 $[32,48]$, and is a tumor suppressor gene which plays a critical role in the regulation of cell growth. It is well known that PTEN antagonizes the proliferative and prosurvival activity of cells induced by activation of PI3k-Akt signaling $[49,50]$. Therefore, we detected the PTEN expression level and Akt phosphorylation level in miR-221 regulated Capan- 2 cells. Our results showed that PTEN was downregulated and $\mathrm{Akt}^{\mathrm{Ser} 43}$ phosphorylation was upregulated in Capan-2 cells transfected with miR-221 mimics, while it displayed a contrary tendency in cells transfected with miR221 inhibitors. We then identified that the proliferative effect of miR-221 on Capan-2 cells could be reversed by Akt inhibition. Meanwhile, overexpression of miR-221 in Capan-2 cells combined with treatment of Akt activator did not show extra effects on cell proliferation. These results indicated that miR-221 may directly target PTEN and thereby activate Akt pathway to induce the proliferation of Capan-2 cells. 
In conclusion, our data provide novel insights into how miR-221 functions to promote PDAC development. The method of inhibiting oncogenesis miR-221 may provide a novel therapeutic approach for patients with PDAC.

\section{Acknowledgments}

This work was supported by the grants from National Natural Science Foundation of China (81170406 to W. Yang; 81070343 and 81370559 to C. Yang; 81400635 to F. Wang), Joint Projects in Major Diseases funding from Shanghai Municipal Commission of Health and Family Planning (2014ZYJB0201 to C. Yang), Joint Projects for Novel Frontier Technology in Shanghai Municipal Hospital from Shanghai Municipal Commission of Health and Family Planning (SHDC12014122 to C. Yang), Shanghai Medical Guide Project from Shanghai Science and Technology Committee (14411971500 to F. Wang), grants from Chinese Foundation for Hepatitis Prevention and Control (TQGB20140141 to F. Wang) and funds from Shanghai Innovation Program (12431901002 to C. Yang).

\section{Disclosure Statement}

The authors declare there are no conflicts of interest.

\section{References}

1 Jemal A, Bray F, Center MM, Ferlay J, Ward E, Forman D: Global cancer statistics. CA Cancer J Clin 2011;61:69-90.

2 Siegel R, Naishadham D, Jemal A: Cancer statistics, 2013. CA Cancer J Clin 2013;63:11-30.

3 Siegel R, Naishadham D, Jemal A: Cancer statistics, 2012. CA Cancer J Clin 2012;62:10-29.

4 Song B, Zheng K, Ma H, Liu A, Jing W, Shao C, Li G, Jin G: MiR-429 determines poor outcome and inhibits pancreatic ductal adenocarcinoma growth by targeting TBK1. Cell Physiol Biochem 2015;35:1846-56.

5 Burris HA, 3rd, Moore MJ, Andersen J, Green MR, Rothenberg ML, Modiano MR, Cripps MC, Portenoy RK, Storniolo AM, Tarassoff P, Nelson R, Dorr FA, Stephens CD, Von Hoff DD: Improvements in survival and clinical benefit with gemcitabine as first-line therapy for patients with advanced pancreas cancer: A randomized trial. J Clin Oncol 1997;15:2403-2413.

6 Bartel DP: Micrornas: Genomics, biogenesis, mechanism, and function. Cell 2004;116:281-297.

7 Song B, Zhang C, Li G, Jin G, Liu C: MiR-940 inhibited pancreatic ductal adenocarcinoma growth by targeting MyD88. Cell Physiol Biochem 2015,35:1167-77.

8 Ambros V: Micrornas: Tiny regulators with great potential. Cell 2001;107:823-826.

9 Lu J, Getz G, Miska EA, Alvarez-Saavedra E, Lamb J, Peck D, Sweet-Cordero A, Ebert BL, Mak RH, Ferrando AA, Downing JR, Jacks T, Horvitz HR, Golub TR: Microrna expression profiles classify human cancers. Nature 2005;435:834-838.

10 Song W, Li Q, Wang L: Modulation of FoxO1 expression by miR-21 to promote growth of pancreatic ductal adenocarcinoma. Cell Physiol Biochem 2015;35:184-90.

11 Callegari E, Gramantieri L, Domenicali M, D'Abundo L, Sabbioni S, Negrini M: Micrornas in liver cancer: A model for investigating pathogenesis and novel therapeutic approaches. Cell Death Differ 2015;22:46-57.

12 Croce CM, Calin GA: Mirnas, cancer, and stem cell division. Cell 2005;122:6-7.

13 Phuah NH, Nagoor NH: Regulation of micrornas by natural agents: New strategies in cancer therapies. Biomed Res Int 2014;2014:804510.

14 Chen WX, Hu Q, Qiu MT, Zhong SL, Xu JJ, Tang JH, Zhao JH: Mir-221/222: Promising biomarkers for breast cancer. Tumour Biol 2013;34:1361-1370.

15 Liu M, Liu J, Wang L, Wu H, Zhou C, Zhu H, Xu N, Xie Y: Association of serum microrna expression in hepatocellular carcinomas treated with transarterial chemoembolization and patient survival. Plos One 2014;9:e109347. 
16 Tao K, Yang J, Guo Z, Hu Y, Sheng H, Gao H, Yu H: Prognostic value of mir-221-3p, mir-342-3p and mir-4915p expression in colon cancer. Am J Transl Res 2014;6:391-401.

17 Yau TO, Wu CW, Dong Y, Tang CM, Ng SS, Chan FK, Sung JJ, Yu J: Microrna-221 and microrna-18a identification in stool as potential biomarkers for the non-invasive diagnosis of colorectal carcinoma. $\mathrm{Br} \mathrm{J}$ Cancer 2014;111:1765-1771.

18 Zheng Q, Peskoe SB, Ribas J, Rafiqi F, Kudrolli T, Meeker AK, De Marzo AM, Platz EA, Lupold SE: Investigation of mir-21, mir-141, and mir-221 expression levels in prostate adenocarcinoma for associated risk of recurrence after radical prostatectomy. Prostate 2014;74:1655-1662.

19 Kawaguchi T, Komatsu S, Ichikawa D, Morimura R, Tsujiura M, Konishi H, Takeshita H, Nagata H, Arita T, Hirajima S, Shiozaki A, Ikoma H, Okamoto K, Ochiai T, Taniguchi H, Otsuji E: Clinical impact of circulating mir-221 in plasma of patients with pancreatic cancer. Br J Cancer 2013;108:361-369.

20 Yamashita R, Sato M, Kakumu T, Hase T, Yogo N, Maruyama E, Sekido Y, Kondo M, Hasegawa Y: Growth inhibitory effects of mir-221 and mir-222 in non-small cell lung cancer cells. Cancer Med 2015;4:551-564.

21 Deer EL, Gonzalez-Hernandez J, Coursen JD, Shea JE, Ngatia J, Scaife CL, Firpo MA, Mulvihill SJ: Phenotype and genotype of pancreatic cancer cell lines. Pancreas 2010;39:425-435.

22 Basu A, Alder H, Khiyami A, Leahy P, Croce CM, Haldar S: Microrna-375 and microrna-221: Potential noncoding rnas associated with antiproliferative activity of benzyl isothiocyanate in pancreatic cancer. Genes Cancer 2011;2:108-119.

23 Sarkar S, Dubaybo H, Ali S, Goncalves P, Kollepara SL, Sethi S, Philip PA, Li Y: Down-regulation of mir-221 inhibits proliferation of pancreatic cancer cells through up-regulation of pten, p27(kip1), p57(kip2), and puma. Am J Cancer Res 2013;3:465-477.

24 Su A, He S, Tian B, Hu W, Zhang Z: Microrna-221 mediates the effects of pdgf-bb on migration, proliferation, and the epithelial-mesenchymal transition in pancreatic cancer cells. Plos One 2013;8:e71309.

25 Jo H, Mondal S, Tan D, Nagata E, Takizawa S, Sharma AK, Hou Q Shanmugasundaram K, Prasad A, Tung JK, Tejeda AO, Man H, Rigby AC, Luo HR: Small molecule-induced cytosolic activation of protein kinase akt rescues ischemia-elicited neuronal death. Proc Natl Acad Sci U S A 2012;109:10581-10586.

26 Semba S, Itoh N, Ito M, Harada M, Yamakawa M: The in vitro and in vivo effects of 2-(4-morpholinyl)-8phenyl-chromone (ly294002), a specific inhibitor of phosphatidylinositol 3'-kinase, in human colon cancer cells. Clin Cancer Res 2002;8: 1957-1963.

27 Bei Y, Song Y, Wang F, Dimitrova-Shumkovska J, Xiang Y, Zhao Y, Liu J, Xiao J, Yang C: Mir-382 targeting ptenakt axis promotes liver regeneration. Oncotarget 2016;7:1584-1597.

28 Li Y, Liang C, Ma H, Zhao Q, Lu Y, Xiang Z, Li L, Qin J, Chen Y, Cho WC, Pestell RG, Liang L, Yu Z: Mir221/222 promotes s-phase entry and cellular migration in control of basal-like breast cancer. Molecules 2014;19:7122-7137.

29 Sun X, Liu B, Zhao XD, Wang LY, Ji WY: Microrna-221 accelerates the proliferation of laryngeal cancer cell line hep-2 by suppressing apaf-1. Oncol Rep 2015;33:1221-1226.

30 Yang F, Wang W, Zhou C, Xi W, Yuan L, Chen X, Li Y, Yang A, Zhang J, Wang T: Mir-221/222 promote human glioma cell invasion and angiogenesis by targeting timp2. Tumour Biol 2015;36:3763-3773.

31 Yang X, Yang Y, Gan R, Zhao L, Li W, Zhou H, Wang X, Lu J, Meng QH: Down-regulation of mir-221 and mir222 restrain prostate cancer cell proliferation and migration that is partly mediated by activation of sirt1. Plos One 2014;9:e98833.

32 Chun-Zhi Z, Lei H, An-Ling Z, Yan-Chao F, Xiao Y, Guang-Xiu W, Zhi-Fan J, Pei-Yu P, Qing-Yu Z, Chun-Sheng K: Microrna-221 and microrna-222 regulate gastric carcinoma cell proliferation and radioresistance by targeting pten. BMC cancer 2010;10:367.

33 Carnero A, Paramio JM: The pten/pi3k/akt pathway in vivo, cancer mouse models. Front Oncol 2014;4:252.

34 Chandarlapaty S, Sawai A, Scaltriti M, Rodrik-Outmezguine V, Grbovic-Huezo O, Serra V, Majumder PK, Baselga J, Rosen N: Akt inhibition relieves feedback suppression of receptor tyrosine kinase expression and activity. Cancer cell 2011;19:58-71.

35 Hers I, Vincent EE, Tavare JM: Akt signalling in health and disease. Cell Signal 2011;23:1515-1527.

36 Janku F, Tsimberidou AM, Garrido-Laguna I, Wang X, Luthra R, Hong DS, Naing A, Falchook GS, Moroney JW, Piha-Paul SA, Wheler JJ, Moulder SL, Fu S, Kurzrock R: Pik3ca mutations in patients with advanced cancers treated with pi3k/akt/mtor axis inhibitors. Mol Cancer Ther 2011;10:558-565. 


\section{Cellular Physiology Cell Physiol Biochem 2016;38:2366-2374 \begin{tabular}{l|l} 
DOI: 10.1159/000445589 & $\begin{array}{l}\text { O 2016 The Author(s). Published by S. Karger AG, Basel } \\
\text { www.karger.com/cpb }\end{array}$
\end{tabular}}

Yang et al.: MiR-221 Promotes Capan-2 Cells Proliferation

37 Steelman LS, Chappell WH, Abrams SL, Kempf RC, Long J, Laidler P, Mijatovic S, Maksimovic-Ivanic D, Stivala F, Mazzarino MC, Donia M, Fagone P, Malaponte G, Nicoletti F, Libra M, Milella M, Tafuri A, Bonati A, Basecke J, Cocco L, Evangelisti C, Martelli AM, Montalto G, Cervello M, McCubrey JA: Roles of the raf/mek/ erk and pi3k/pten/akt/mtor pathways in controlling growth and sensitivity to therapy-implications for cancer and aging. Aging 2011;3:192-222.

38 Zoncu R, Efeyan A, Sabatini DM: Mtor: From growth signal integration to cancer, diabetes and ageing. Nat Rev Mol Cell Biol 2011;12:21-35.

39 Li C, Siragy HM: (pro)renin receptor regulates autophagy and apoptosis in podocytes exposed to high glucose. Am J Physiol Endocrinol Metab 2015;309:E302- 310.

40 Zhu M, Li J, Wang K, Hao X, Ge R, Li Q: Isoquercitrin inhibits hydrogen peroxide-induced apoptosis of ea.Hy926 cells via the pi3k/akt/gsk3beta signaling pathway. Molecules 2016 21;21. pii: E356. doi: 10.3390/molecules21030356. DOI: 10.3390/molecules21030356.

41 Chen W, Zheng R, Zhang S, Zhao P, Li G, Wu L, He J: Report of incidence and mortality in china cancer registries, 2009. Chin J Cancer Res 2013;25:10-21.

42 Jemal A, Siegel R, Xu J, Ward E: Cancer statistics, 2010. CA Cancer J Clin 2010;60:277-300.

43 Hirata K, Egawa S, Kimura Y, Nobuoka T, Oshima H, Katsuramaki T, Mizuguchi T, Furuhata T: Current status of surgery for pancreatic cancer. Dig Surg 2007;24:137-147.

44 Bae HJ, Jung KH, Eun JW, Shen Q Kim HS, Park SJ, Shin WC, Yang HD, Park WS, Lee JY, Nam SW: Microrna-221 governs tumor suppressor hdac6 to potentiate malignant progression of liver cancer. J Hepatol 2015;63:408-419.

45 Nassirpour R, Mehta PP, Baxi SM, Yin MJ: Mir-221 promotes tumorigenesis in human triple negative breast cancer cells. Plos One 2013;8:e62170.

46 Panarelli NC, Chen YT, Zhou XK, Kitabayashi N, Yantiss RK: Microrna expression aids the preoperative diagnosis of pancreatic ductal adenocarcinoma. Pancreas 2012;41:685-690.

47 Yang CJ, Shen WG, Liu CJ, Chen YW, Lu HH, Tsai MM, Lin SC: Mir-221 and mir-222 expression increased the growth and tumorigenesis of oral carcinoma cells. J Oral Pathol Med 2011;40:560-566.

48 Zhao G, Cai C, Yang T, Qiu X, Liao B, Li W, Ji Z, Zhao J, Zhao H, Guo M, Ma Q Xiao C, Fan Q Ma B: Microrna-221 induces cell survival and cisplatin resistance through pi3k/akt pathway in human osteosarcoma. Plos One 2013;8:e53906.

49 Li R, He JL, Chen XM, Long CL, Yang DH, Ding YB, Qi HB, Liu XQ: Mir-200a is involved in proliferation and apoptosis in the human endometrial adenocarcinoma cell line hec-1b by targeting the tumor suppressor pten. Mol Biol Rep 2014;41:1977-1984.

50 Worby CA, Dixon JE: Pten. Annu Rev Biochem 2014;83:641-669. 